\title{
Meeting report: Research topics in gastrointestinal disease IV
}

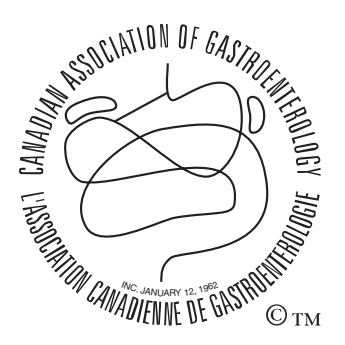

En français voir page 167

Gordon R Greenberg MD FRCP, University of Toronto, Toronto, Ontario;

Ken Croitoru MD FRCP, MCMaster University, Hamilton, Ontario;

Derek McKay PhD, Chair, CAG Research Committee; McMaster University, Hamilton, Ontario;

Paul Sinclair, Executive Director, CAG

$\mathrm{C}$ Yurrent advances in therapeutics of gastrointestinal (GI) diseases are a direct result of the rapid developments in fundamental research of cellular and molecular biology and its specific application to defining the normal physiology of the GI tract and the pathogenesis of mechanisms underlying disease processes. The Canadian GI research community has contributed greatly to these efforts and continues to be a world leader in all disciplines relevant to GI disease. Much of this success has been achieved by fostering an excellent cohort of graduate and postgraduate research trainees involved in GI research at institutes across Canada. Many of these trainees are funded by the Canadian Association of Gastroenterology (CAG) in collaboration with the Canadian Institutes of Health Research, a number of industry partners, and the Crohn's and Colitis Foundation of Canada (1).

In recognition of the value of outstanding research contributions by Canadian GI trainees, and to promote and encourage the continued efforts of the basic and clinical science graduate and postgraduate research trainees, the CAG, in conjunction with AstraZeneca Canada Inc and the Canadian Institutes of Health Research, held the Fourth Symposium on Research Topics in Gastrointestinal Disease on October 22 to 24,2004 . The goal of this meeting was to provide research trainees with the opportunity to formally present their original work to both their peers and a selection of faculty from across Canada. In addition, trainees actively participated in the discussion of these papers in an open forum setting. This year's program again comprised a series of superb presentations describing cutting-edge research; 40 podium scientific presentations of basic and clinical GI-related research were held, highlighting areas such as inflammatory bowel disease, Helicobacter pylori, GI motility, epithelial ion transport, mechanisms of colon cancer and GI infection. Importantly, the meeting also provided a venue at which trainees could meet their peers from across Canada and initiate collaborative opportunities, thus developing contacts for their future research careers and the future of Canadian GI research. As noted by Dr Philip Sherman (Past President of the CAG) during a presentation to the attendees on an academic career in GI research, "This meeting provides a unique opportunity for emerging investigators to establish contacts that will last throughout their future careers".

Participants evaluated the meeting overall as excellent, and described the experience as a rewarding and superb learning forum. Thus, as a result of this enormously successful symposium, the organizing committee, the CAG and AstraZeneca Canada Inc are committed to holding this meeting on an annual basis. Plans are already underway for the fall of 2005, at which time research abstract submissions relating to all facets of GI health and disease will once again be welcomed. Canadian investigators with basic and clinical GI research programs are strongly requested to lend support to this important endeavour by encouraging the participation of their trainees and graduate students.

ACKNOWLEDGEMENTS: The organizers would particularly like to thank AstraZeneca Canada Inc for their generous support of this meeting, the fourth of its kind in a series that will continue to advance gastroenterology in Canada. In addition, we wish to thank the faculty, Alison Fox-Robichaud, Kevan Jacobson, Karen Madsen and Andrew Stadnyk for their commitment and valuable contributions to this meeting.

\footnotetext{
REFERENCES

1. McKay D, Daniels S. Canadian Association of Gastroenterology - Canadian Institutes of Health Research - pharmaceutical partner postdoctoral operating fellowship programme:

An outstanding success that continues to excel! Can J Gastroenterol 2003;17:437-9.
}

The CAG is proud to acknowledge its Benefactor Corporate Sponsors:
Abbott Laboratories Ltd.
AstraZeneca Canada Inc.
Axcan Pharma Inc. Janssen-Ortho Inc.
Pfizer Canada Inc.
Schering Canada Inc. 


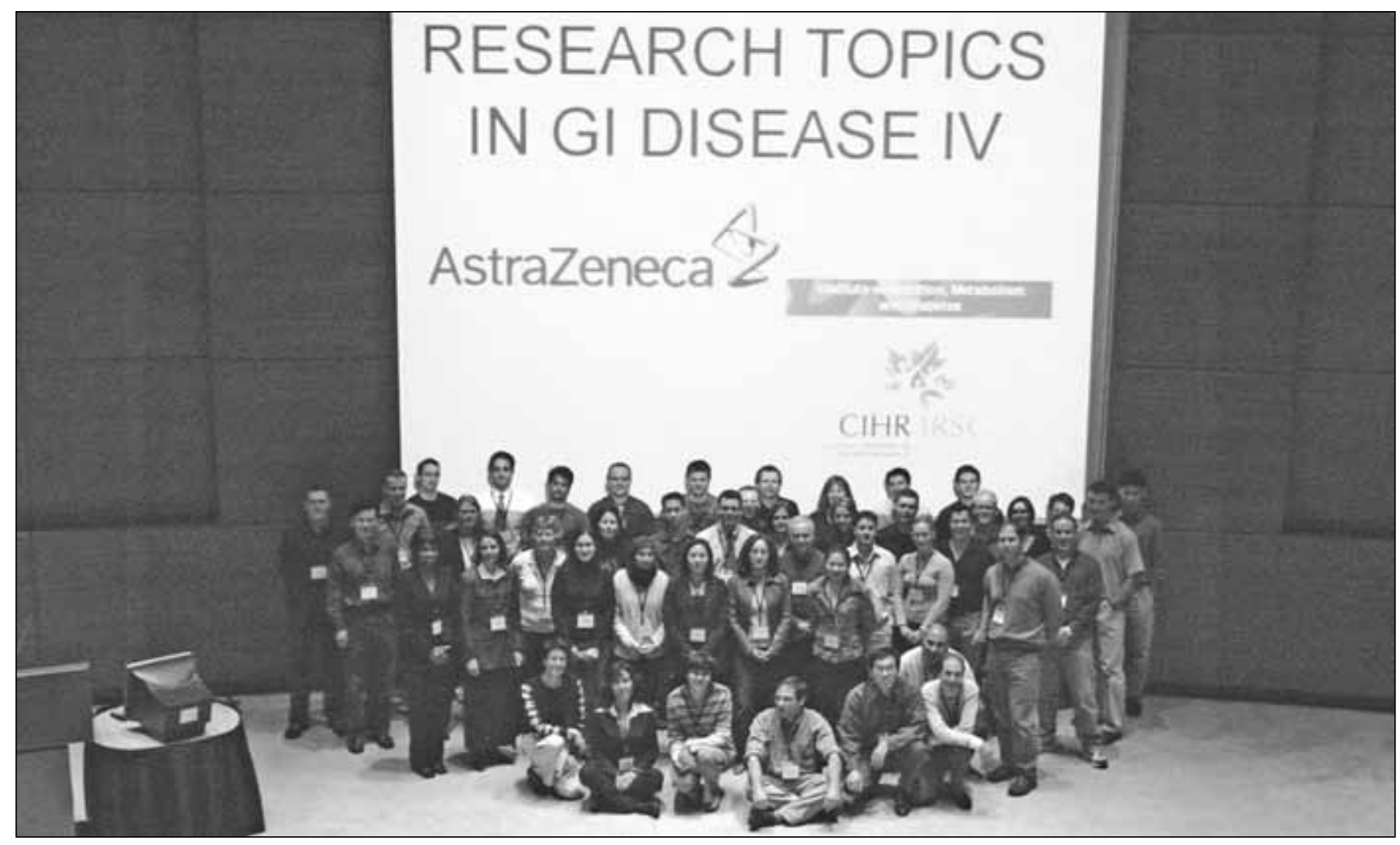

PARTICIPANTS

Dr Maureen Ajueboe, Calgary Mr Eric Albert, Halifax Ms Michelle Buresi, Calgary Mr Wayland Cheng, Wheaton County Ms Marnie Duncan, Calgary Mr Jason Fedwick, Calgary Mr Andrew Flynn, Calgary Ms Caroline Francoeur, Sherbrooke Ms Esther Galindo-Mata, Toronto Ms Mélanie Gareau, Hamilton Ms Nasim Heshmati, Ottawa Mr Niall Hyland, Calgary Ms Zhiqi Jian, Vancouver
Mr Ahmed Kayssi, Kingston Ms Fareeha Khan, Halifax Mr Dirk Lange, Ontario Dr Haihuang Liu, Kingston Dr Alan Lomax, Calgary Mr Rex Pillai, Vancouver Ms Jennifer Raoul, Halifax Mr Colin Reardon, Hamilton Mr Jacob Rullo, Hamilton Ms Amy Sharaf, Toronto Dr Manuel Silva, Hamilton Ms linga Teller, Sherbrooke Dr Mauricio Terebizink, Toronto
Dr Dave Thiel, Edmonton Ms Ashley Tremblay, Waterloo Mr Jacques Van Der Merwe, Calgary Mr SRV Vijayakumar, London Mr John Walker, Edmonton Mr Thomas Walters, Toronto Mr James Watson, Hamilton Mr Ron Wells, Kingston Mr Vincent Wong, Kingston Dr Linda Yu, Calgary Dr Renata Zamardo, Calgary Dr Stella Zamuner, Calgary Ms Pengfei Zhou, Hamilton

\section{FACULTY}

Dr Ken Croitoru, Hamilton

Dr Alison Fox-Robichaud, Hamilton

Dr Gordon R Greenberg, Toronto

\author{
Dr Kevan Jacobson, Vancouver \\ Dr Karen Madsen, Edmonton \\ Dr Derek M McKay, Hamilton
}

Dr Philip M Sherman, Toronto

Dr Andrew W Stadnyk, Halifax 


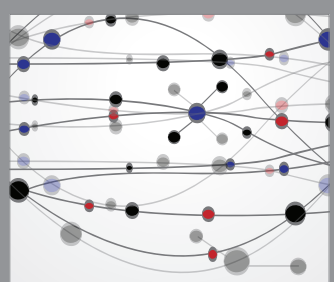

The Scientific World Journal
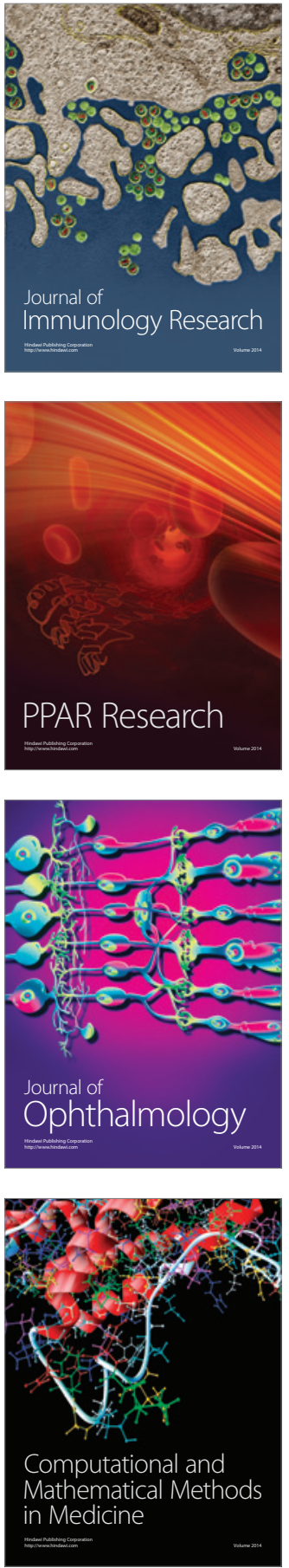

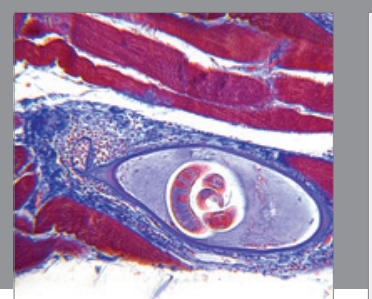

Gastroenterology Research and Practice

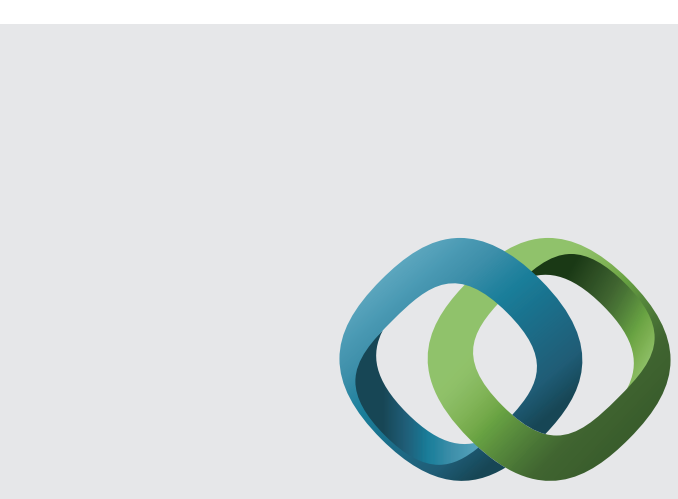

\section{Hindawi}

Submit your manuscripts at

http://www.hindawi.com
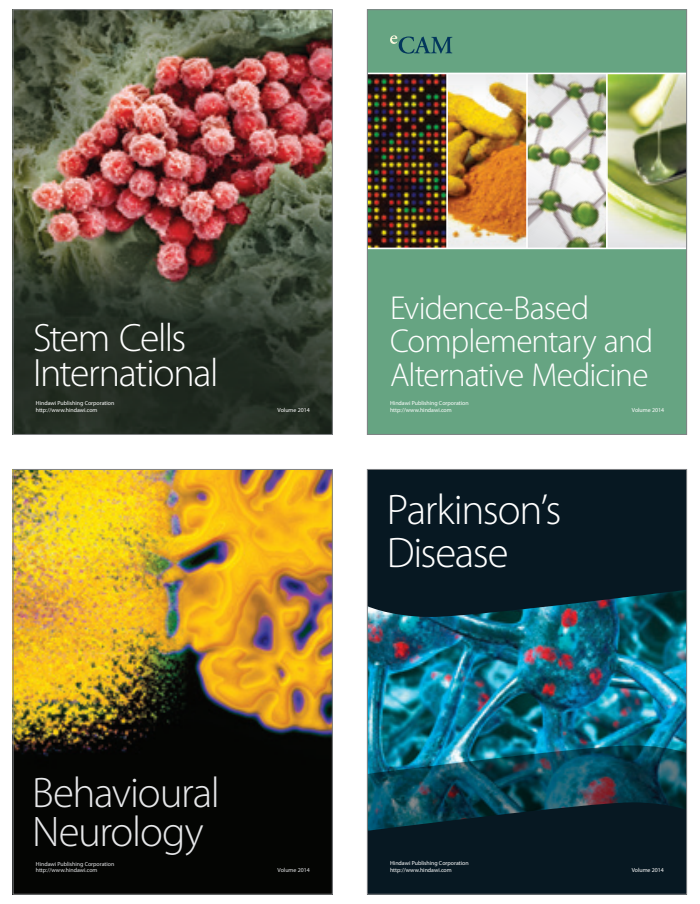
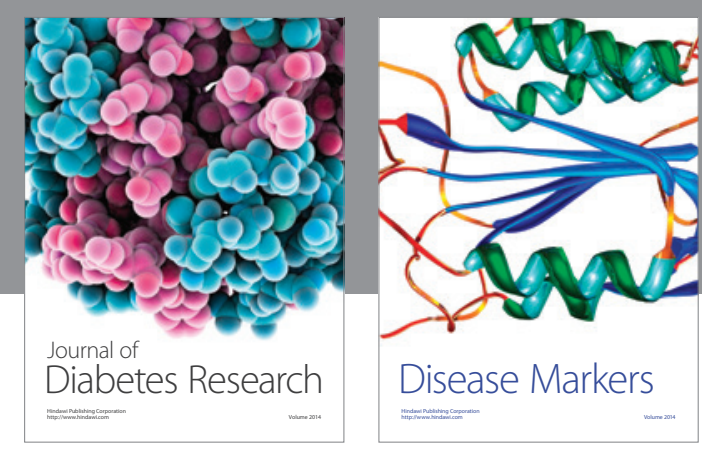

Disease Markers
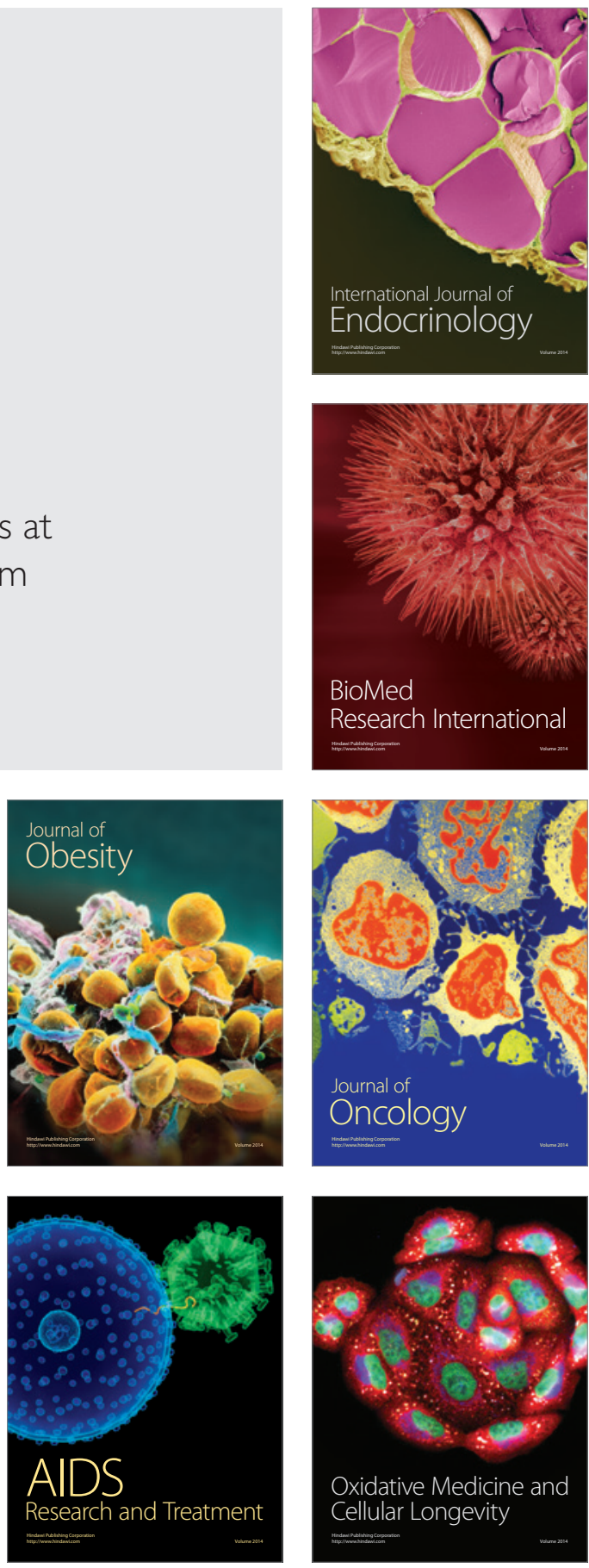